\title{
Fourier-transformed infrared spectroscopy, physicochemical and biochemical properties of chondroitin sulfate and glucosamine as supporting information on quality control of raw materials
}

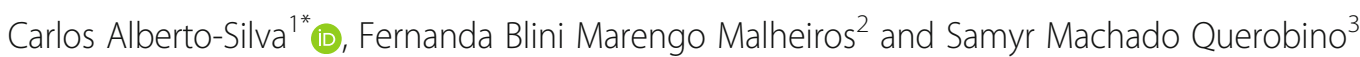

\begin{abstract}
Background: Chondroitin sulfate (CS) and glucosamine (GLCN) are recommended for the restoration of the articular cartilage surface in patients affected by osteoarthritis. They are commercialized as pharmaceutical-grade products and as food supplements, and there are reports that they do not undergo the strict quality controls of pharmaceuticals. Herein, we evaluated the physicochemical parameters of two raw materials (CS and GlcN) obtained from two distinct suppliers in Brazil and compare the obtained data with the product specification provided by the manufacturer. Also, the homogeneity and purity grade of samples were analyzed by FT-IR spectroscopy.

Results: The organoleptic properties and solubility of CS and GICN samples obtained from pharmacy analyses and the supplier's specifications are in accordance with the standards required by the Brazilian Health Regulatory Agency (ANVI $\mathrm{SA}$ ). However, the intraclass correlation coefficient (ICC) and Bland Altman analysis of $\mathrm{pH}$ and the density values of samples are statistically different between the suppliers. In addition, FT-IR analyses indicated that there is nonhomogeneity in the CS and GlcN samples tested, showing that both manufacturers distribute the drugs in different concentrations, although both declare the same concentration in the product technical specifications.
\end{abstract}

Conclusion: In summary, our study demonstrated that physicochemical parameters are insufficient to ensure product quality, and it is necessary to implement a more efficient protocol to ensure the quality of the final product.

Keywords: Chondroitin sulfate, Glucosamine, Quality control, Raw material, FT-IR, Physicochemical parameters

\section{Highlights}

FT-IR analyses of raw materials for compounding pharmacies.

Chondroitin sulfate and glucosamine and control quality.

Chondroitin sulfate and glucosamine quality in compounding pharmacies.

\footnotetext{
* Correspondence: carlos.asilva@ufabc.edu.br

${ }^{1}$ Natural and Humanities Sciences Center, Experimental Morphophysiology Laboratory Federal University of ABC (UFABC), Rua Arcturus, n 03, Bloco

Delta, São Bernardo do Campo, SP 09606-070, Brazil

Full list of author information is available at the end of the article
}

Quality control of raw materials using FT-IR spectroscopy.

\section{Background}

Osteoarthritis is a progressive, degenerative joint and musculoskeletal disease with a huge incidence and economic impact [1]. It involves mechanical overloading of the articular joints, loss of cartilage and synovial fluids, bone degradation, inflammation, and reduction of mobility and quality of life [2]. Pharmacological therapy includes analgesics or non-steroidal anti-inflammatory drugs [3] or, as an alternative, chondroitin sulfate (CS)

\section{Springer Open}

() The Author(s). 2020 Open Access This article is licensed under a Creative Commons Attribution 4.0 International License, which permits use, sharing, adaptation, distribution and reproduction in any medium or format, as long as you give appropriate credit to the original author(s) and the source, provide a link to the Creative Commons licence, and indicate if changes were made. The images or other third party material in this article are included in the article's Creative Commons licence, unless indicated otherwise in a credit line to the material. If material is not included in the article's Creative Commons licence and your intended use is not permitted by statutory regulation or exceeds the permitted use, you will need to obtain permission directly from the copyright holder. To view a copy of this licence, visit http://creativecommons.org/licenses/by/4.0/. 
and glucosamine sulfate (GlcN) as anti-osteoarthritis agents [4-6]. CS and GlcN are recommended by the European League Against Rheumatism (EULAR) and the Osteoarthritis Research Society International (OARSI) guidelines for the treatment of symptomatic knee and hip osteoarthritis, providing relief of pain and increasing joint mobility $[7,8]$.

CS is a glycosaminoglycan that occurs naturally in the extracellular matrix of connective tissues, e.g., bone, cartilage, skin, ligaments, and tendons $[9,10]$. GlcN is produced in the human body as a precursor to glycosylated lipids, proteins, glycosaminoglycans (GAGs), and proteoglycans [5]. Commercially available CS is extracted from the cartilage of different animals [11]. The structural heterogeneity of CS obtained from different animal sources has been reported in the literature [12], and some pharmaceutical preparations also present contamination with other GAGs due to failures during the purification process [12-14]. GlcN can be obtained through the extraction of chitin from crustacean shells followed by both alkaline or acid hydrolyzes or by de novo chemical synthesis [5, 9], and it is commercialized as stabilized salt of glucosamine or glucosamine sulfate [5]. Despite that, CS and GlcN are combined in pharmaceutical preparations and in food supplements to be orally administered as anti-osteoarthritis active principles even in long-term therapy [15]. The EULAR and the European Society for Clinical and Economic Aspects of Osteoporosis and Osteoarthritis and Musculoskeletal Disease (ESCEO) have recommended daily dosages of CS and GlcN between 800 and $1200 \mathrm{mg}$ and between 1250 and $1500 \mathrm{mg}$, respectively $[4,8]$.

All raw materials authorized for usage in pharmaceutical formulations must comply with pharmacopeial specifications, including a list of tests, analytical procedures, and tolerance limits, or acceptance criteria to which products should conform [16]. These specifications are among the main screening tools used by regulatory authorities in analytical testing for quality assessment and express the quality standards for the concerned products [17]. In Brazil, pharmaceutical preparations of bovine CS in combination with $\mathrm{GlcN}$ for oral administration are available as capsule and sachet formulations and are routinely prepared in the compounding pharmacy [18]. They represent an important economic resource in the Brazilian pharmaceutical market, comprising a total of $8 \%$ of the turnover in the entire pharmaceutical sector, according to the Brazilian Association of Compounding Pharmacists [19], because the medicines are offered at lower prices than the industrialized formulation. Therefore, an emphasis on product quality is necessary with the growth of this sector, which is regulated by the Brazilian Health Regulatory Agency (ANVISA), created by federal law in 1999 [20].
ANVISA established quality control parameters for manufactured products, preparations, and the effectiveness of compounded drugs [21-24]. Routinely, the raw material is submitted to physicochemical analyses, such as organoleptic evaluations, solubility, $\mathrm{pH}$, melting point, and density, according to the Brazilian pharmacopeial specifications [25]. However, analytical analyses of results' assessment, even in compliance, were able to identify different products and manufacturers with a trend toward the lower tolerance limits. Because the preparations of CS, whether or not they are combined with GlcN, present extensive chemical variations depending on their animal source $[4,12,14,26-28]$, it is necessary to establish a comprehensive set of analytical protocols to assess the fine structure, physicochemical characteristics, and purity of each type of CS and GlcN present in these pharmaceutical products. In the present study, we evaluated the physicochemical parameters of two raw materials used in pharmaceutical formulations for osteoarthritis treatment ( $\mathrm{CS}$ and $\mathrm{GlcN}$ ) in compounding pharmacy, according to Brazilian pharmacopeia specifications and analytical data from post-marketing and recognized by ANVI SA [20], and compared the obtained data with the product specification report provided by the manufacturer. Also, FT-IR analyses were performed to verify the homogeneity and purity grade of CS and GlcN samples obtained from two distinct suppliers.

\section{Methods \\ Chemical reagents}

All chemical reagents used in the present study were of analytical grade (purity higher than 95\%) and purchased from Sigma-Aldrich Corporation (USA).

\section{Collection of samples}

Chondroitin sulfate $(n=50$; CS) and glucosamine $(n=$ 50; GlcN) samples, with molecular formulas of $\mathrm{C}_{14} \mathrm{H}_{19} \mathrm{NO}_{14} \mathrm{~S}(\mathrm{MW}=457.4 \mathrm{~g} / \mathrm{mol})$ and $\left(\mathrm{C}_{6} \mathrm{H}_{14} \mathrm{NO}_{5}\right)$ $2 \mathrm{SO}_{4} .2 \mathrm{KCl}(\mathrm{MW}=605.52 \mathrm{~g} / \mathrm{mol})$, respectively, were obtained in a solid pharmaceutical form from two different Brazilian pharmaceutical companies. The names of the manufacturers were kept anonymous due to ethical principles; the manufacturers are identified here as supplier 1 (S1) and supplier 2 (S2), and both are duly licensed by the competent sanitary authority in Brazil. Samples were submitted for physicochemical evaluation, including the determination of organoleptic characteristics (description of color and odor), $\mathrm{pH}$, solubility, and density. All methods of performing these analyses were conducted according to the Brazilian pharmacopeia specifications and analytical data from post-marketing [25] and were recognized by ANVISA, responsible for pharmaceutical product regulation in Brazil [20]. In summary, the data 
obtained were compared to the product specification report provided by the manufacturer.

\section{Organoleptic properties}

The color, odor, taste, and texture of the samples were analyzed in $0.1 \mathrm{~g}$ of CS and GlcN spread evenly over nonporous white paper and visually compared to supplier specifications in concordance with standards concerning comparative observations with supplier specifications as previously published [29].

\section{Solubility}

CS and GlcN samples $(0.1 \mathrm{~g})$ were weighed with the aid of a metal spatula on an analytical balance $\left(\right.$ Gehaka $^{\circ}$ model BG-1000) and transferred to a test tube previously identified with the names of samples and the solvents appropriated (distilled water or ethanol). The GlcN sample was considered freely soluble when $0.1 \mathrm{~g}$ of sample was added to $1 \mathrm{~mL}$ of water, following complete dissolution. The reference for insolubility was $0.01 \mathrm{~g}$ of GlcN added to $90 \mathrm{~mL}$ of ethanol for total dissolution. Separately, a CS sample was considered soluble when $0.1 \mathrm{~g}$ was dissolved in $3 \mathrm{~mL}$ of water [29].

\section{Apparent density}

The apparent density is a direct relationship between the mass of the sample and its specific volume measured in a graduated cylinder, according to ANVISA specifications [30]. For both CS and GlcN, $5 \mathrm{~g}$ of the sample was weighed and transferred to a graduated cylinder and then immediately sealed. With standardized moves and a fixed height, the powder was settled to remove the air on a smooth surface until a constant volume was achieved. Then, the final volume was noted. The reference density values are between 0.9332 and $0.70 \mathrm{~g} / \mathrm{mL}$ for CS and GlcN, respectively [31].

\section{Determination of $\mathrm{pH}$}

We used a pH meter (Marconi ${ }^{\circ}$, PA 200 model) with a CS aqueous solution at $1 \%(\mathrm{w} / \mathrm{v})$ and $\mathrm{GlcN} 5 \%(\mathrm{w} / \mathrm{v})$ at laboratory temperatures approximating $25{ }^{\circ} \mathrm{C}$. The $\mathrm{pH}$ reference to CS was between 5.0 and 7.5, while that for GlcN was between 3.5 and 5.0, according to the literature [31].

\section{Fourier-transformed infrared (FT-IR) spectroscopy}

For the FT-IR spectroscopy, $5 \mathrm{mg}$ of CS and GlcN samples were weighed on an analytical balance (TE214sSartorio $^{\circ}$ ) and mixed with $95 \mathrm{mg}$ of potassium bromide ( $\mathrm{KBr}-$ Sigma-Aldrich $\left.{ }^{\circ} \rightarrow 99 \%\right)$. Then, the samples were pressed into $\mathrm{KBr}$ disks. All samples were analyzed by transmission Fourier-transformed infrared spectroscopy on a 640 -IR FT-IR spectrometer (Varian-Agilent ${ }^{\circ}$ ). The FT-IR measurements were recorded at frequencies between 4000 and $800 \mathrm{~cm}^{-1}$. Each spectrum was obtained by averaging 256 scans recorded at a resolution of $2 \mathrm{~cm}^{-1}$.

\section{Statistical analyses}

The homogeneity of variance between the sample groups was tested by Levene's test. The adherence of the data to the normal curve was tested using the KolmogorovSmirnov and Shapiro-Wilk tests. The variables were both parametric and non-parametric distributions and presented as mean \pm standard deviation (SD) of three independent experiments $(n=3)$ in duplicate. For comparison between groups (Pharmacy, S1 and S2) we used a one-way analysis of variance (ANOVA) for betweengroup comparisons followed by a Tukey's post hoc test for multiple comparisons. To determine the correlation of variables between the pharmacy and suppliers, we used the intraclass correlation coefficient (ICC) and considered excellent agreement values to be those between 0.80 and 1.0 , moderate agreement values to be those between 0.60 and 0.79 , and low agreement values to be those less than 0.60. Additionally, a Bland-Altman analysis was conducted. For the nonparametric results, we used the Mann-Whitney test. For statistical analyses, we used the software SPSS 20.0 for Windows (SPSS Inc., Chicago, IL) or GraphPad Prism 6.0 (GraphPad Software, Inc., La Jolla, CA). Values of $p<0.05$ were considered to be statistically significant.

\section{Results}

\section{Physicochemical properties of CS and GlcN}

The organoleptic properties obtained from pharmacy analyses of CS showed white powder and odor characteristics, while GlnN was an almost white powder in all samples. All CS samples were soluble in water, while GlcN samples were soluble in water and practically insoluble in alcohol (Table 1).

The data regarding the density and $\mathrm{pH}$ of both raw materials are shown in Fig. 1. The $\mathrm{pH}$ of CS samples did not show a difference between the suppliers and pharmacy (Fig. 1a), but the GlcN samples were different between S1 and S2 (Fig. 1b). There was a significant difference between the density values of CS samples between the suppliers and pharmacy (Fig. 1c), while there was a difference between the GlcN samples of the suppliers and the data obtained from the pharmacy and S1 and S2 (Fig. 1d). Additionally, for the pH of CS, the ICC values were 0.525 for $\mathrm{S} 1$ and -0.474 for $\mathrm{S} 2$, while for GlcN, the samples were 0.480 and 0.845 , respectively. The ICC values for the density of CS samples were 0.998 for both suppliers while the values for $\mathrm{GlcN}$ samples were -0.064 and 0.134 for S1 and S2, respectively.

The Bland-Altman analysis was employed to compare the $\mathrm{pH}$ and density data of $\mathrm{CS}$ and GlcN samples 
Table 1 Organoleptic properties and solubility of chondroitin sulfate (CS) and glucosamine sulfate (GlcN). The data represent the qualitative analysis obtained from pharmacy and technical specifications provided by the suppliers (S1 and S2). All methods of performing these analyses were carried out according to the Brazilian pharmacopeia specifications and analytical data from postmarketing [25] and recognized by the Brazilian Health Regulatory Agency (ANVISA), responsible for pharmaceutical product regulation in Brazil [20]

\begin{tabular}{|c|c|c|c|c|c|}
\hline \multicolumn{2}{|c|}{ Samples } & $\begin{array}{l}\text { Pharmacy (S1 samples) } \\
\text { Control quality }\end{array}$ & $\begin{array}{l}\text { Pharmacy (S2 samples) } \\
\text { Control quality }\end{array}$ & Supplier 1 (S1) & Supplier 2 (S1) \\
\hline \multirow[t]{2}{*}{ CS } & $\begin{array}{l}\text { Organoleptic } \\
\text { characteristics }\end{array}$ & $\begin{array}{l}\text { White powder; } \\
\text { characteristic odor }\end{array}$ & $\begin{array}{l}\text { White powder; } \\
\text { characteristic odor }\end{array}$ & $\begin{array}{l}\text { Fine white amorphous powder, } \\
\text { cream or ivory; characteristic } \\
\text { odor }\end{array}$ & $\begin{array}{l}\text { Powder cream to nearly white } \\
\text { amorphous thin ivory, moderately } \\
\text { hygroscopic }\end{array}$ \\
\hline & Solubility & Water-soluble & Water-soluble & Water-soluble & Water-soluble \\
\hline \multirow[t]{2}{*}{ GIcN } & $\begin{array}{l}\text { Organoleptic } \\
\text { characteristics }\end{array}$ & Almost white powder & Almost white powder & White crystalline powder & Cream-colored powder almost white \\
\hline & Solubility & $\begin{array}{l}\text { Soluble in water and } \\
\text { practically insoluble in } \\
\text { alcohol }\end{array}$ & $\begin{array}{l}\text { Soluble in water and } \\
\text { practically insoluble in } \\
\text { alcohol }\end{array}$ & $\begin{array}{l}\text { Easily soluble in water and } \\
\text { practically insoluble in ethanol }\end{array}$ & $\begin{array}{l}\text { Soluble in water and practically } \\
\text { insoluble in acetone, alcohol, and } \\
\text { isopropyl alcohol }\end{array}$ \\
\hline
\end{tabular}

obtained by the pharmacy and provided by S1 and S2. For the $\mathrm{pH}$ of CS samples, our data demonstrated concordance with values near and along with the mean of the differences for S1 (Fig. 2a) and S2 (Fig. 2b). Something similar occurred for density testing, with the values being in the range of $95 \%$ for S1 (Fig. 2c), while S2 underestimated the density compared to the pharmacy (Fig. 2d). In the GlcN samples, we showed that both suppliers overestimated (Fig. 3a) and underestimated (Fig. $3 \mathrm{~b}$ ) the actual $\mathrm{pH}$ value, while the stated $\mathrm{pH}$ value for the pharmacy sample was accurate. The density analyses were overestimated in S1 (Fig. 3c) and underestimated in S2 (Fig. 3d) relative to the accuracy of the stated values and the sample obtained by the pharmacy.

\section{Characterization of CS and GlcN by FT-IR}

The FT-IR spectra analysis showed the presence of characteristic peaks for CS (Fig. 4) and GlcN (Fig. 5) for both suppliers. Additionally, the absence of exogenous
A

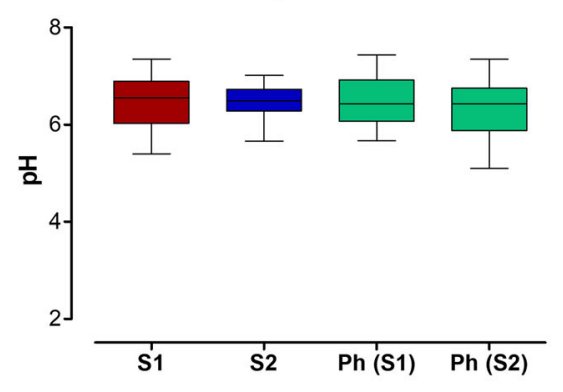

C

Density CS

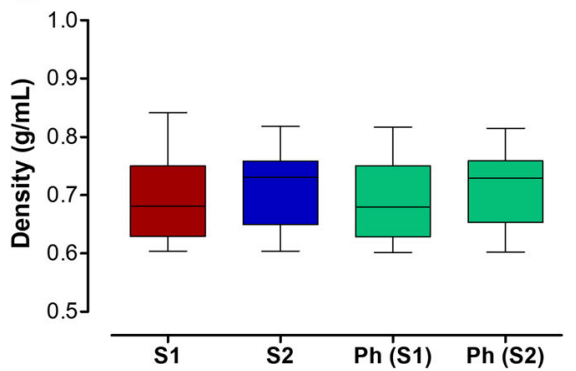

B

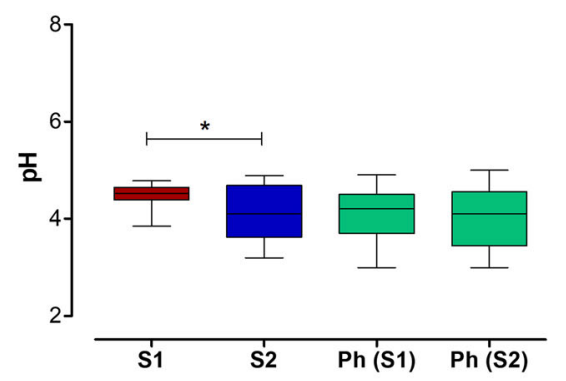

D

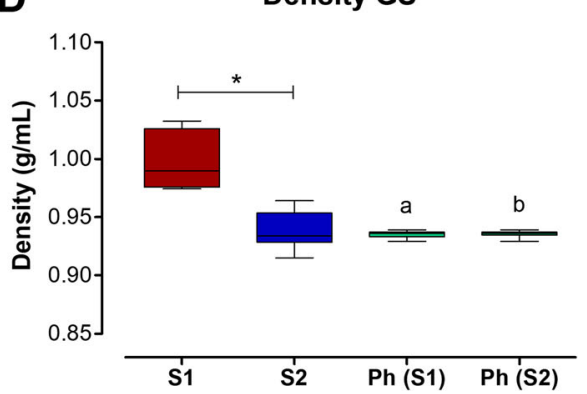

Fig. 1 Physicochemical properties of chondroitin sulfate (CS) and glucosamine sulfate potassium chloride (GlcN) samples provided by suppliers (S1 and S2) and obtained from the pharmacy. Comparative analyses of pH values for CS (a) and GlcN (b) samples. Comparative analyses of apparent density values for CS (c) and GICN (d) samples. Values are expressed as mean \pm standard deviation and analyzed by one-way ANOVA followed by Tukey's post-test. ${ }^{*} p<0.05$ between S1 and S2; ${ }^{a} p<0.05$ in relation to S1; ${ }^{b} p<0.05$ when compared to S2. S1, supplier 1 ; S2, supplier 2; Ph (S1), pharmacy analyses from supplier 1 samples; Ph (S2), pharmacy analyses from supplier 2 samples 

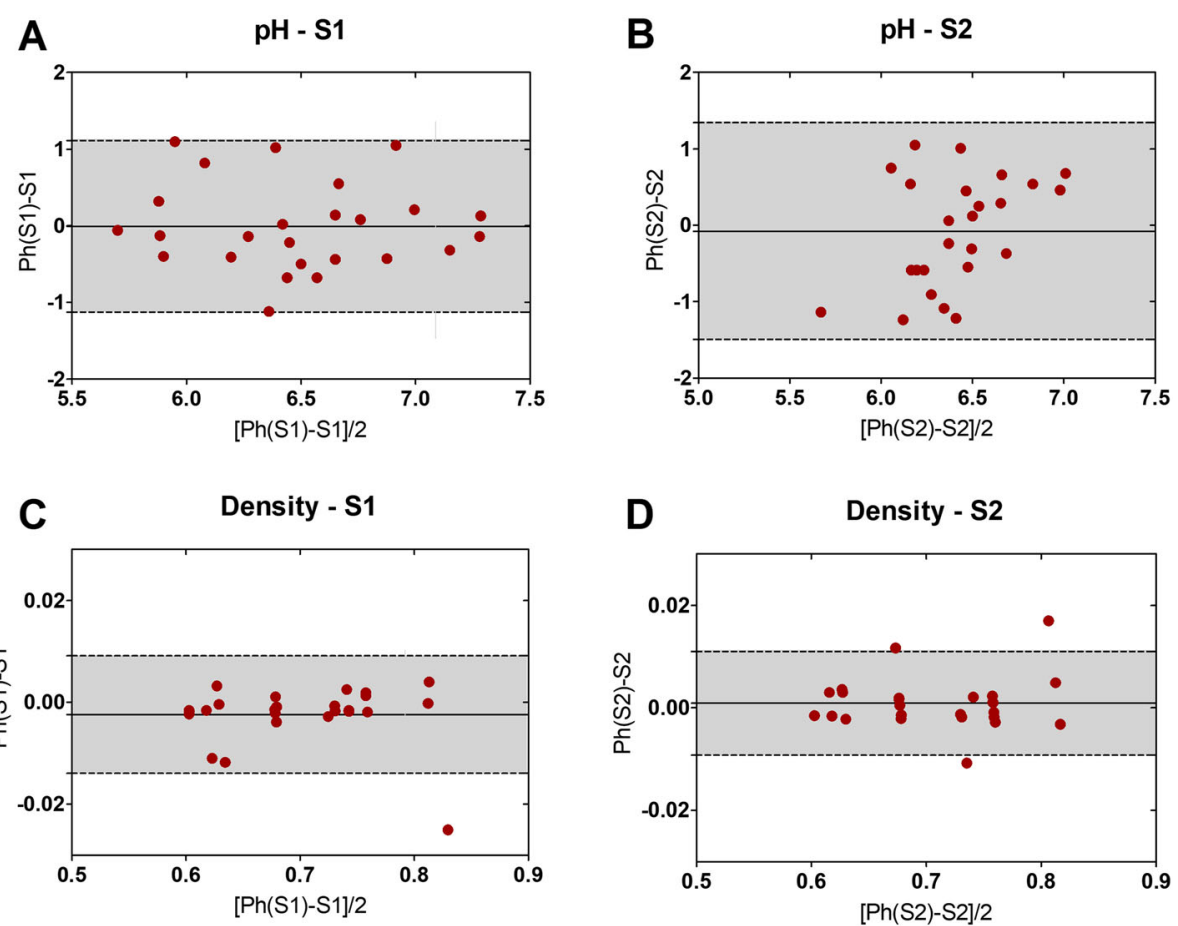

Fig. 2 Bland-Altman analysis of the $\mathrm{pH}$ and density for the chondroitin sulfate (CS) samples of S1 and S2 vs. pharmacy. Analyses of pH values for S1 (a) and S2 (b). Analyses of density values for S1 (c) and S2 (d). S1, supplier 1; S2, supplier 2; Ph (S1), pharmacy analyses from supplier 1 samples; Ph (S2), pharmacy analyses from supplier 2 samples

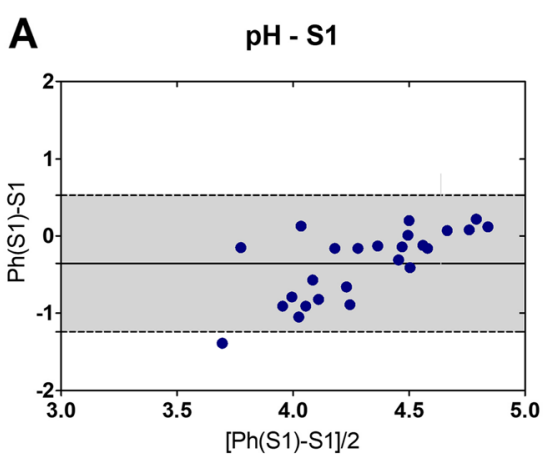

B

pH - S2

\section{C}

Density - S1

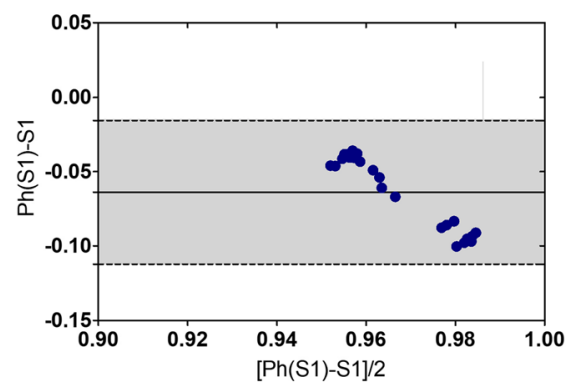

D Density - S2
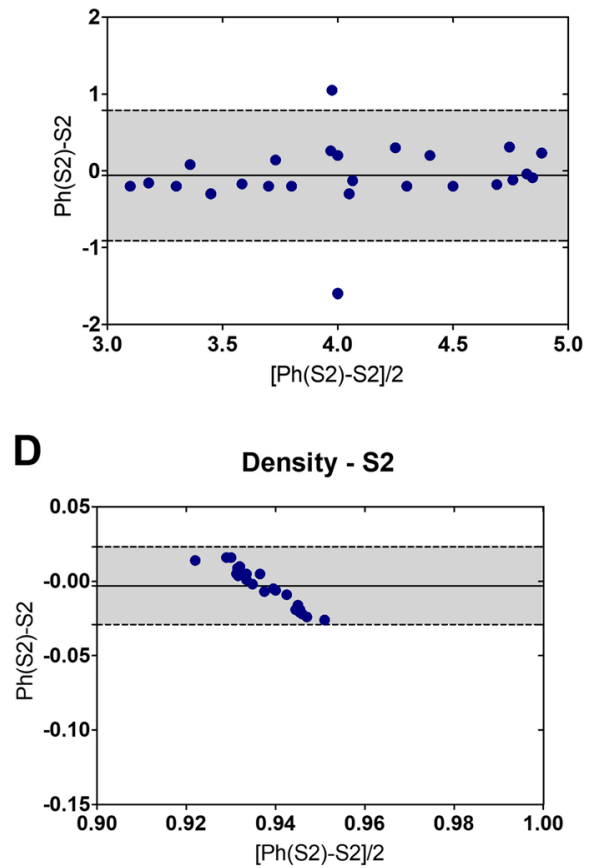

Fig. 3 Bland-Altman analysis of the pH and density for the glucosamine sulfate potassium chloride (GlcN) samples of S1 and S2 vs. pharmacy. Analyses of pH values for S1 (a) and S2 (b). Analyses of density values for S1 (c) and S2 (d). S1, supplier 1; S2, supplier 2; Ph (S1), pharmacy analyses from supplier 1 samples; Ph (S2), pharmacy analyses from supplier 2 samples 

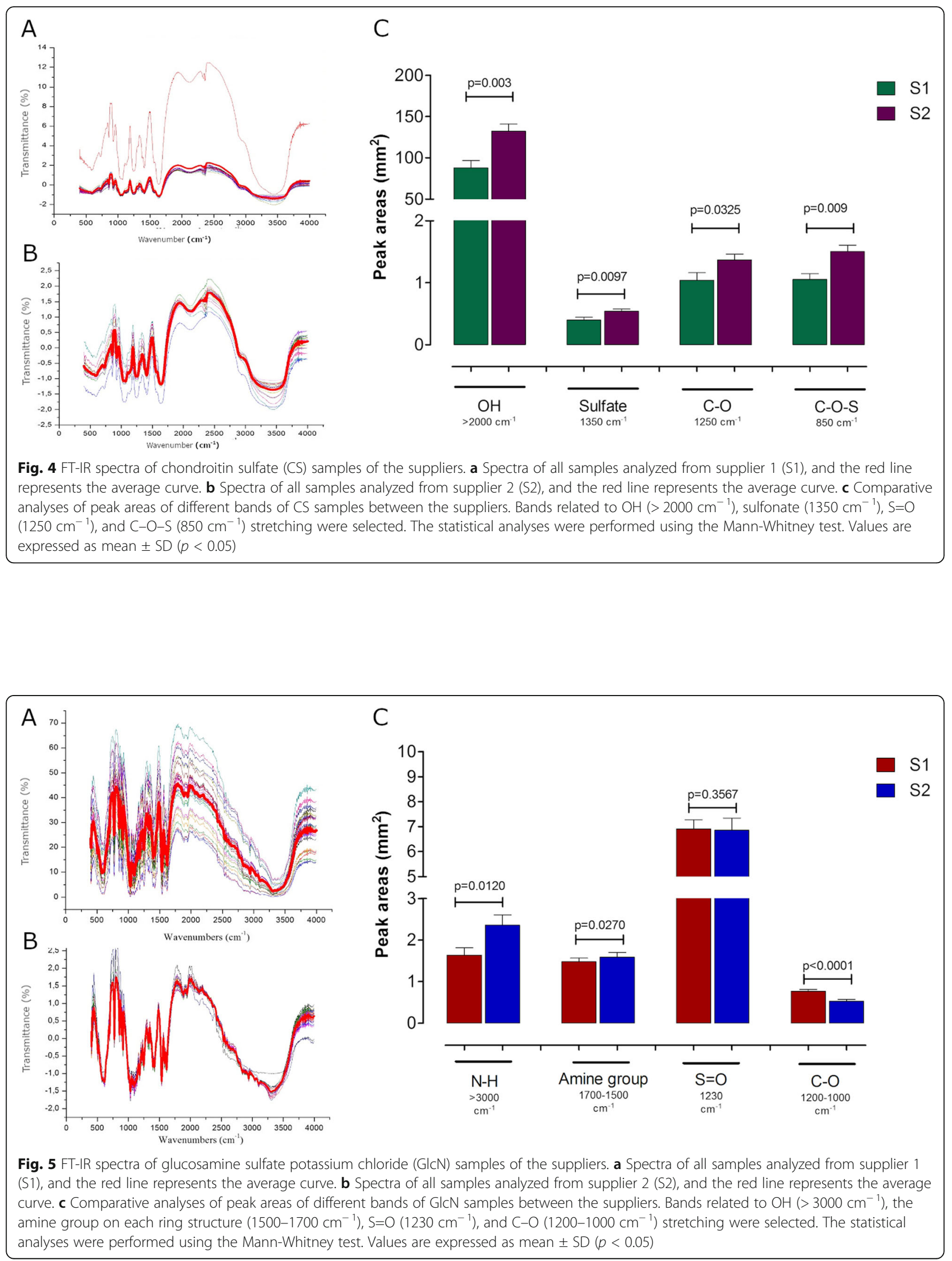
functional groups suggests that the compounds are pure, though there were variations in the bands' intensity in samples from the same supplier.

CS samples from S1 demonstrated good reproducibility, with only one sample exceeding the average intensity (Fig. 4a); the samples from S2 showed no homogeneous distribution around the mean (Fig. 4b). Comparative analyses of peak areas of different bands of CS samples between the suppliers are shown in Fig. 4c. In the CS spectra, the region above $2000 \mathrm{~cm}^{-1}$ was dominated by the $\mathrm{OH}$ stretching vibration. The band at $1350 \mathrm{~cm}^{-1}$ was due to the sulfate. The band at $1250 \mathrm{~cm}^{-1}$ has been assigned to $\mathrm{S}=\mathrm{O}$. The peak at $850 \mathrm{~cm}^{-1}$ was due to the $\mathrm{C}-\mathrm{O}-\mathrm{S}$ vibration. Additionally, the peak areas of $\mathrm{OH}$, sulfate, $\mathrm{S}=\mathrm{O}$, and $\mathrm{C}-\mathrm{O}-\mathrm{S}$ bands of $\mathrm{S} 1$ samples were statistically smaller than those of the S2 samples (Fig. 4c).

The GlcN spectra are similar to those of glucose, as they share very similar structures and do not contain chemical contaminants, though some exceptions were identified due to the presence of the sulfate and amine functional groups. The GlcN samples from S1 present large variations (Fig. 5a), while the sample from S2 shows a homogeneous distribution around the mean (Fig. 5b). The identified peaks were $\mathrm{N}-\mathrm{H}$ band above $3000 \mathrm{~cm}^{-1}$; several peaks between 1500 and $1700 \mathrm{~cm}^{-1}$ that were due to the amine group on each ring structure; an $\mathrm{S}=\mathrm{O}$ band seen at around $1230 \mathrm{~cm}^{-1}$; and a $\mathrm{C}-\mathrm{O}$ band between 1200 and $1000 \mathrm{~cm}^{-1}$ (Fig. 5c). In addition, the bands intensities of $\mathrm{N}-\mathrm{H}$, amine group, and $\mathrm{C}-\mathrm{O}$ bands were different between suppliers (Fig. 5c).

\section{Discussion}

In the present study, we demonstrated that organoleptic properties, solubility, pH, and density of CS and GlcN samples, two raw materials obtained from two different Brazilian pharmaceutical companies, are in accordance with the standards required by ANVISA, responsible for pharmaceutical product regulation in Brazil [20]. Despite this, the $\mathrm{pH}$ and density values of both samples were different between the suppliers and opened the possibility that parameters required by the ANVISA cannot be sufficient to assess the appropriate quality control of raw materials. Indeed, FT-IR analyses indicated that there is non-homogeneity in the CS and GlcN samples tested, indicating that both manufacturers distribute the drugs in different concentrations which could compromise the quality and therapeutic efficiency of the pharmaceutical formulation used for osteoarthritis treatment. These formulations are prepared in pharmacies authorized by the Health Surveillance secretariats, which can be either state or municipal, according to ANVISA Directors' Collegiate Resolution (RDC) 67/2007 [26], updated by RDC 44/2009 [32] and RDC 41/2012 [33], which define the
Good Manufacturing Practices (GMP) for compounded medicines for human use in pharmacies.

Quality control encompasses a group of measurements intended to ensure the production of numerous medicines and other products that meet the standards of identity, activity, content, purity, effectiveness, and safety [25]. The specifications and quality tests for pharmaceutical raw materials and formulations are described in detail in pharmacopeia monographs, including average weight, weight uniformity, hardness, disintegration time, dissolution, and dose uniformity [25, 34]. All raw materials are submitted to organoleptic evaluations, solubility, $\mathrm{pH}$, melting point, and density, according to the Brazilian pharmacopeial specifications [25]. In the present study, the organoleptic properties and solubility of CS and GlcN samples obtained from pharmacy analyses and the supplier's specifications are in accordance with the standards required by ANVISA [18, 21, 24, 25, 29, 30].

CS and GlcN are available as pharmaceutical-grade products, and the latter have great variations in preparation, composition, purity, and effects $[1,12,35]$. Some products contain a negligible amount of CS; among samples with reasonable amounts, in vitro testing showed widely varying effects [11, 36, 37]. This could be related to contaminants, which depend on the origin, production, and purification process $[11,38]$. In our study, the comparative analyses of the physicochemical parameters of CS and GlcN between pharmacy tests and technical specifications provided by two Brazilian suppliers showed that the $\mathrm{pH}$ and density values are statistically different, although they agree with the standards required by ANVISA [18, 21, 24, 25, 29, 30]. In addition, while the values are under the standards required by ANVISA, ICC analyses for $\mathrm{pH}$ and density values demonstrated a low correlation between the data obtained from the pharmacy and the specification report provided by the manufacturer.

The CS density presents excellent concordance; however, the GlcN density showed low reproducibility for the two suppliers in the Bland-Altman analyses. The agreement values for different suppliers in terms of $\mathrm{pH}$ and density for S1 remained along and near the mean differences for CS, which are important values for the agreement parameter. For the GlcN samples, the agreement values sometimes either underestimated or overestimated values relative to pharmacy estimates. However, it is understood that more tests would be required to approve or disapprove the raw material, as there was no satisfactory agreement with the methods used, considering the range between the limits of agreement. It is worth mentioning that the values found in the tests are in the range required for each raw material according to Martindale and Parfitt [31] and the GMP of RDCs [26, 32, 33]. 
It is important to say that the margin between the minimum and maximum values of the physicochemical parameters required by ANVISA [26] is very large, which may compromise the quality of the product, change the concentration of the active ingredient in these formulations, and, consequently, reduce the therapeutic efficacy of pharmaceutical compounding. In fact, in our study, FT-IR analyses indicated non-homogeneity in the CS and GlcN samples between S1 and S2, showing that both manufacturers distribute the drugs in different concentrations, although both declare the same concentration in the product technical specifications.

The purity of raw materials was evaluated by FT-IR, which identified only functional groups attached to molecules of CS and GlcN, according to the literature [3942]. Analyses of peak areas of different bands of CS samples showed that region spectra above $2000 \mathrm{~cm}^{-1}$ were dominated by the $\mathrm{OH}$ stretching vibration [41]. The band at $1350 \mathrm{~cm}^{-1}$ was due to the sulfate. The band at $1250 \mathrm{~cm}^{-1}$ has been assigned to $\mathrm{S}=\mathrm{O}$ corresponding to the band assignment by Cabassi et al. [39]. The peak at $850 \mathrm{~cm}^{-1}$ was due to the $\mathrm{C}-\mathrm{O}-\mathrm{S}$ vibration according to Honda et al. [40]. The spectrum of GlcN is similar to that of glucose, as they share very similar structures [41] and it was possible to identify the $\mathrm{N}-\mathrm{H}$ band above the $3000 \mathrm{~cm}^{-1}$, amine group between 1500 and $1700 \mathrm{~cm}^{-1}$, $\mathrm{S}=\mathrm{O}$ band around $1230 \mathrm{~cm}^{-1}$, and $\mathrm{C}-\mathrm{O}$ band between 1200 and $1000 \mathrm{~cm}^{-1}$.

Although the raw materials meet the current legislation regarding the physicochemical parameters in Brazil, the vibrational analysis of bands from CS and GlcN revealed that the samples have different intensities in the absorption peaks. In $\mathrm{CS}$, the $\mathrm{N}-\mathrm{H}$, amine group, on each ring structure and $\mathrm{C}-\mathrm{O}$ bands were different between suppliers. Similarly, the peak areas of $\mathrm{OH}$, sulfate, $\mathrm{S}=\mathrm{O}$, and $\mathrm{C}-\mathrm{O}-\mathrm{S}$ bands of GlcN samples were also different. The decrease in radiant energy detected when a beam of radiation passes through a material medium is proportional to the beam power and quantity of a radiationabsorbing substance found in its path through the medium, according to Beer's law [43]. Therefore, a correlation can be made between the intensity of the peaks and the concentration of the substance by calculating the area of the peak. Thus, our data indicated nonhomogeneity in the concentration of the CS and GlcN samples from the same supplier as well as between S1 and S2, suggesting that both are distributing the pharmaceutical form in different concentrations, although both declare the same concentration in the product technical specifications. Additionally, these differences in the concentration of drugs could explain the large variation of the physicochemical data obtained between the pharmacy and the technical specifications of suppliers.
The implantation of RDC 67/2007 [26] was considered a great advance in Brazil, though we believe that the strategies adopted for the assessment of drug quality should be more accurate because, as shown in our study, attending to physicochemical standards is not sufficient to guarantee the quality and reproducibility of the production of pharmaceutical compounding and can negatively impact the quality of these products.

\section{Conclusion}

In our study, commercial samples of CS and GlcN, two raw materials widely used in pharmaceutical formulations for osteoarthritis treatment, obtained from two different suppliers are non-homogenous according to FTIR spectroscopy, physicochemical and biochemical analyses, suggesting that both can be distributed as the pharmaceutical form in different concentrations.

\section{Abbreviations}

ANOVA: One-way analysis of variance; ANVISA: Brazilian Health Regulatory Agency; CS: Chondroitin sulfate; ESCEO: European Society for Clinical and Economic Aspects of Osteoporosis and Osteoarthritis and Musculoskeletal Disease; EULAR: European League Against Rheumatism; EULAR: European League Against Rheumatism; FT-IR: Fourier-transformed infrared spectroscopy; GAGs: Glycosaminoglycans; GlcN: Glucosamine sulfate; GMP: Good Manufacturing Practices; ICC: Intraclass correlation coefficient; MW: Molecular weight; OARSI: Osteoarthritis Research Society International; RDC: ANVISA Directors' Collegiate Resolution

\section{Acknowledgments}

We are grateful to Dra Patrícia A. da Ana for the technical assistance in the Fourier-transformed infrared (FT-IR) spectroscopy analysis.

\section{Authors' contributions}

SMQ performed the FT-IR analyses and interpreted the data. FBMM performed the physicochemical assays of raw materials. CAS designed the work and was responsible for drafting the manuscripts. All authors read and approved the final manuscript.

\section{Funding}

The authors would like to thank FAPESP (São Paulo Research Foundation) and CAPES (Coordination for the Improvement of Higher Education Personnel) for their financial support (Finance Code 001).

Availability of data and materials

Data and materials are available upon request.

Ethics approval and consent to participate

Not applicable.

Consent for publication

Not applicable.

Competing interests

The authors declare that they have no competing interests.

\section{Author details}

${ }^{1}$ Natural and Humanities Sciences Center, Experimental Morphophysiology Laboratory Federal University of ABC (UFABC), Rua Arcturus, $n^{\circ}$ 03, Bloco Delta, São Bernardo do Campo, SP 09606-070, Brazil. ²Adamantina University Center - UNIFAl, Rua Nove de Julho, 730, Adamantina, SP 17800-000, Brazil. ${ }^{3}$ Universidade do Estado de Minas Gerais - UEMG, Av. Juca Stockler, 1130, Bairro Belo Horizonte, Passos, MG 37900-106, Brazil. 
Received: 20 July 2020 Accepted: 23 September 2020

Published online: 23 November 2020

\section{References}

1. Volpi N (2019) Chondroitin sulfate safety and quality. Molecules 24. https:// doi.org/10.3390/molecules24081447

2. Chevalier $X$, Conrozier $T$ (2017) Access to highly purified chondroitin sulfate for appropriate treatment of osteoarthritis: a review. Med Access @ Point Care 1:maapoc.0000022 . doi.https://doi.org/10.5301/maapoc.0000022

3. Goldring MB, Otero M (2011) Inflammation in osteoarthritis. Curr Opin Rheumatol 23:471-478. https://doi.org/10.1097/BOR.0b013e328349c2b1

4. Restaino OF, Finamore R, Stellavato A, Diana P, Bedini E, Trifuoggi M, De Rosa M, Schiraldi C (2019) European chondroitin sulfate and glucosamine food supplements: a systematic quality and quantity assessment compared to pharmaceuticals. Carbohydr Polym:222. https:/doi.org/10.1016/j.carbpol.2019.114984

5. Agiba AM (2017) Nutraceutical formulations containing glucosamine and chondroitin sulphate in the treatment of osteoarthritis: emphasis on clinical efficacy and formulation challenges. Int J Curr Pharm Res 9:1. https://doi. org/10.22159/ijcpr.2017v9i2.17380

6. Miller KL, Clegg DO (2011) Glucosamine and chondroitin sulfate. Rheum Dis Clin N Am 37:103-118. https://doi.org/10.1016/j.rdc.2010.11.007

7. Bruyère $\mathrm{O}$, Cooper $\mathrm{C}$, Al-Daghri NM, Dennison EM, Rizzoli R, Reginster JY (2018) Inappropriate claims from non-equivalent medications in osteoarthritis: a position paper endorsed by the European Society for Clinical and Economic Aspects of Osteoporosis, Osteoarthritis and Musculoskeletal Diseases (ESCEO). Aging Clin Exp Res 30:111-117

8. Henrotin $Y$, Lambert C (2013) Chondroitin and glucosamine in the management of osteoarthritis: an update topical collection on complementary and alternative medicine. Curr Rheumatol Rep 15. https:// doi.org/10.1007/s11926-013-0361-z

9. Collin EC, Carroll O, Kilcoyne M, Peroglio M, See E, Hendig D, Alini M, Grad S, Pandit A (2017) Ageing affects chondroitin sulfates and their synthetic enzymes in the intervertebral disc. Signal Transduct Target Ther 2. https:// doi.org/10.1038/sigtrans.2017.49

10. Tat SK, Pelletier JP, Vergés J, Lajeunesse D, Montell E, Fahmi H, Lavigne M, Martel-Pelletier J (2007) Chondroitin and glucosamine sulfate in combination decrease the pro-resorptive properties of human osteoarthritis subchondral bone osteoblasts: a basic science study. Arthritis Res Ther 9. https://doi.org/10.1186/ar2325

11. Martel-Pelletier J, Farran A, Montell E, Vergés J, Pelletier JP (2015) Discrepancies in composition and biological effects of different formulations of chondroitin sulfate. Molecules 20:4277-4289

12. Santos GRC, Piquet AA, Glauser BF, Tovar AMF, Pereira MS, Vilanova E, Mourão PAS (2017) Systematic analysis of pharmaceutical preparations of chondroitin sulfate combined with glucosamine. Pharmaceuticals:10. https://doi.org/10.3390/ph10020038

13. Pomin VH, Piquet AA, Pereira MS, Mourão PAS (2012) Residual keratan sulfate in chondroitin sulfate formulations for oral administration. Carbohydr Polym 90:839-846. https://doi.org/10.1016/j.carbpol.2012.06.009

14. Restaino OF, Finamore R, Diana P, Marseglia M, Vitiello M, Casillo A, Bedini E, Parrilli M, Corsaro MM, Trifuoggi M, De Rosa M, Schiraldi C (2017) A multianalytical approach to better assess the keratan sulfate contamination in animal origin chondroitin sulfate. Anal Chim Acta 958:59-70. https://doi.org/ 10.1016/j.aca.2016.12.005

15. Kilborne AH, Hussein $H$, Bertone AL (2017) Effects of hyaluronan alone or in combination with chondroitin sulfate and $\mathrm{N}$-acetyl-d-glucosamine on lipopolysaccharide challenge-exposed equine fibroblast-like synovial cells. Am J Vet Res 78:579-588. https://doi.org/10.2460/ajvr.78.5.579

16. World Health Organization (2016) Expert Committee on Specifications for Pharmaceutical Preparations. Fiftieth report

17. Neves EO, de Sales PM, Silveira D (2020) Pharmacopeial specifications and analytical data from post-marketing quality sampling and testing programs: a perspective beyond out-of-specification results. J Pharm Biomed Anal:178. https://doi.org/10.1016/j.jpba.2019.112935

18. Ministério da Saúde; ANVISA; Brazil (2019) Resolução Da Diretoria Colegiada - RDC n 275, de 9 de abril de 2019. Diário Of da União - DOU 69:138

19. ANFARMAG - Associação Nacional de Farmacêuticos Brazilian Association of Compounding Pharmacists. https://anfarmag.org.br/home. Accessed 10 Jun 2020

20. Presidência da República;Brazil (1999) Law nº.782, define Brazilian Health Regulatory Agency (ANVISA). https:/legislacao.presidencia.gov.br/ficha/?/legisla/ legislacao.nsf/Niw_Identificacao/lei\%209.782-19998OpenDocument, Brazil
21. Ministério da Saúde, ANVISA (2019) Resolução Da Diretoria Colegiada - RDC 330, nº 20 de Dezembro de 2019. Diário Of da União - DOU 234:85

22. Nathan AJ, Scobell A (2012) How China sees America. Foreign Aff 91. https://doi.org/10.1017/CBO9781107415324.004

23. Ministério da Saúde (2004) Decreto-Lei n 594/2004, 2 de Junho - Boas práticas a observar na preparação de medicamentos manipulados em farmácia de oficina e hospitalar. Diário da República nº 168 I Série:

24. Ministério da Saúde; ANVISA; Brazil (2018) Resolução Da Diretoria Colegiada - RDC n² 214, DE 7 de fevereiro de 2018. Diário Of da União - DOU 36:5565

25. Ministério da Saúde; ANVISA; Brazil (2012) Brazilian Pharmacopoeia 5th edition

26. Ministério da Saúde; ANVISA; Brazil (2007) Resolução da Diretoria Colegiada - RDC n 67 de 08 de outubro de 2007. Diário Of da União - DOU 195:29

27. Garnjanagoonchorn W, Wongekalak L, Engkagul A (2007) Determination of chondroitin sulfate from different sources of cartilage. Chem Eng Process Process Intensif 46:465-471. https://doi.org/10.1016/j.cep.2006.05.019

28. Anacleto $S$ da $S$, Borges MMC, de Oliveira HL, Vicente AR, de Figueiredo EC, de Oliveira MAL, Borges BJP, de Oliveira MA, Borges W de S, Borges KB (2018) Evaluation of physicochemical properties as supporting information on quality control of raw materials and veterinary pharmaceutical formulations. J Pharm Anal 8:168-175 . doi.https://doi.org/10.1016/j.jpha. 2018.01.001

29. Ministério da Saúde; ANVISA; Brazil (2016) Resolução Da Diretoria Colegiada - RDC n 87, de 21 de novembro de 2008. Diário Of da União - DOU 123:41

30. Agência Nacional de Vigilânia Sanitária (2012) Guia para Avaliação de Segurança de Produtos Cosméticos Guia para Avaliação de Segurança de Produtos Cosméticos, 2a ed

31. O'Rourke A (2010) Martindale: The Complete Drug Reference. In: American Journal of Health-System Pharmacy, pp 321-321

32. Ministério da Saúde; ANVISA; Brazil (2009) Resolução da Diretoria Colegiada - RDC n 44 de 17 de agosto de 2009. Diário Of da União - DOU 157:78

33. Ministério da Saúde; ANVISA; Brazil (2012) Resolução da Diretoria Colegiada - RDC n 41 de 26 de julho de 2012. Diário Of da União - DOU 145:59

34. Usp-Nf (2013) <1092> The dissolution procedure: development and validation. United States Pharmacop Natl Formul 31:1-11

35. Volpi N (2007) Analytical aspects of pharmaceutical grade chondroitin sulfates. J Pharm Sci 96:3168-3180. https://doi.org/10.1002/jps.20997

36. Volpi N (2009) Quality of different chondroitin sulfate preparations in relation to their therapeutic activity. J Pharm Pharmacol 61:1271-1280. https://doi.org/10.1211/jpp/61.10.0002

37. Tat SK, Pelletier JP, Mineau F, Duval N, Martel-Pelletier J (2010) Variable effects of 3 different chondroitin sulfate compounds on human osteoarthritic cartilage/chondrocytes: relevance of purity and production process. J Rheumatol 37:656-664. https://doi.org/10.3899/jrheum.090696

38. Stellavato A, Restaino OF, Vassallo V, Finamore R, Ruosi C, Cassese E, De Rosa M, Schiraldi C (2019) Comparative analyses of pharmaceuticals or food supplements containing chondroitin sulfate: are their bioactivities equivalent? Adv Ther 36:3221-3237. https://doi.org/10.1007/s12325-019-01064-8

39. Cabassi F, Casu B, Perlin AS (1978) Infrared absorption and raman scattering of sulfate groups of heparin and related glycosaminoglycans in aqueous solution. Carbohydr Res 63:1-11. https://doi.org/10.1016/S00086215(00)80924-6

40. Honda S, Yuki H, Takiura K (1974) Use of fourier transform 13 C nuclear magnetic resonance spectroscopy for sulfate placement in chondroitin sulfates. J Biochem 76:209-211. https://doi.org/10.1093/oxfordjournals. jbchem.a130548

41. Foot M, Mulholland M (2005) Classification of chondroitin sulfate A, chondroitin sulfate C, glucosamine hydrochloride and glucosamine 6 sulfate using chemometric techniques. J Pharm Biomed Anal 38:397-407. https:// doi.org/10.1016/j.jpba.2005.01.026

42. Movasaghi Z, Rehman S, Rehman IU (2008) Fourier transform infrared (FTIR) spectroscopy of biological tissues. Appl Spectrosc Rev 43:134-179. https:// doi.org/10.1080/05704920701829043

43. Abitan H, Bohr H, Buchhave P (2008) Correction to the Beer-LambertBouguer law for optical absorption. Appl Opt 47:5354-5357. https://doi.org/ 10.1364/AO.47.005354

\section{Publisher's Note}

Springer Nature remains neutral with regard to jurisdictional claims in published maps and institutional affiliations. 